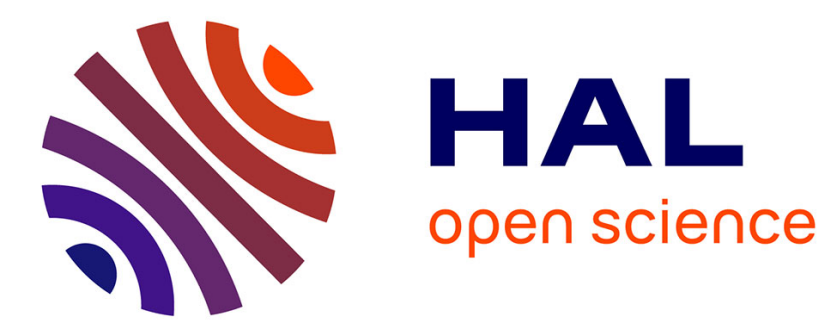

\title{
3D genome organization: setting the stage and introducing its players
}

Daan Noordermeer

\section{To cite this version:}

Daan Noordermeer. 3D genome organization: setting the stage and introducing its players. Briefings in

Functional Genomics and Proteomics, 2020, 19 (2), pp.69-70. 10.1093/bfgp/elaa006 . hal-02995866

\section{HAL Id: hal-02995866 \\ https://hal.science/hal-02995866}

Submitted on 9 Nov 2020

HAL is a multi-disciplinary open access archive for the deposit and dissemination of scientific research documents, whether they are published or not. The documents may come from teaching and research institutions in France or abroad, or from public or private research centers.
L'archive ouverte pluridisciplinaire HAL, est destinée au dépôt et à la diffusion de documents scientifiques de niveau recherche, publiés ou non, émanant des établissements d'enseignement et de recherche français ou étrangers, des laboratoires publics ou privés. 
$\underline{\text { Editorial }}$

\section{D genome organization: setting the stage and introducing its players}

The introduction of Chromosome Conformation Capture (3C) by Job Dekker and colleagues in 2002, followed by derivatives that incorporate high-throughput sequencing-most notably $\mathrm{Hi}$-C - have transformed the study of eukaryotic 3D genome organization $[1,2]$. Whereas prior imaging-based studies mostly focused on the positioning of genomic regions within the cell nucleus or relative to other structures, 3C-based approaches directly revealed higher-order chromatin structure. Their widespread use has identified, in mammalian cells, a multi-level organization that incorporates multimegabase chromatin compartments, which are linked to overall transcriptional output, sub-megabase Topologically Associating Domains (TADs), which are demarcated by insulator proteins like CTCF, and at the smallest scales ensembles of chromatin loops, which link regulatory elements, and contact domains, which correspond to clustered regions that carry the same histone modifications (see e.g. [27]).

In this special issue of Briefings in Functional Genomics on 3D genome organization, and two preceding publications, a generation of scientists whose careers paralleled this still young field take the stage to comment on the most important past and future developments. Their reviews cover a broad spectrum of topics related to 3D genome structure, ranging from available technologies and their applications, via structuration and dynamics in different eukaryotic models and cell types, the advances in polymer physics-inspired computational simulations to explain this structuration, to its importance for human disease. Combined, this collection provides a comprehensive overview how far this dynamic field has advanced in less than two decades, and where the future may bring us.

Übelmesser and Papantonis, in a review that precedes this special issue, provide a detailed introduction of the technologies to study 3D genome organization, with a particular emphasis on Hi-C. Moreover, they discuss how new developments, both based on genomics and imaging, are helping to improve the resolution, to reduce experimental biases, to provide new insights into the cell-to-cell variation and to identify the different factors and nuclear substructures that shape 3D genome organization [8].

In four reviews, either in this special issue or recently published, the overall concepts of 3D genome organization are introduced, related to what is known about their structure, function and dynamics in different eukaryotic systems [9-12]. Pachano and colleagues discuss chromatin architecture in mammalian embryonic stem cells, with a particular focus on the repressive Polycomb group $(\mathrm{PcG})$ proteins and associated histone modifications. Within stem cells, $\mathrm{PcG}$ proteins acts as a major multi-scale organizer of the genome that incorporates both local and distant interactions among repressed regions within an otherwise active nuclear environment. Such an organization may be 
particularly beneficial for these pluripotent cells, as it provides both an efficient means of repression while maintaining a flexible differentiation potential [9]. In a similar vein, Van Schoonhoven and colleagues review how the dynamic nature of $3 \mathrm{D}$ genome organization in mammalian lymphocytes $(\mathrm{B}$ and $\mathrm{T}$ cells) is linked to transcriptional regulation and cellular identity. Moreover, they highlight the importance of the multi-scale organization and how transcription factors can drive changes in this organization during cellular differentiation and lymphocyte activation. Finally, they discuss how 3D genome organization is actively involved in the rearrangement of antigen-receptor loci, which is a unique feature of lymphocytes [10]. Both these reviews thus emphasize the shared importance of a dynamic and multi-scale 3D genome organization in mammalian cells.

The reviews by Grob and by Moretti and colleagues provide overviews of 3D genome organization in two other well-characterized eukaryotic models; flowering plants and Drosophila melanogaster. In both plants and insects, the genome adopts a dynamic multi-scale organization that incorporates compartments, TAD-like structures and chromatin loops, confirming the universal nature of multi-level organization in higher eukaryotes. Nonetheless, interesting differences are discussed as well, including differences in size scales, in factors that structure the genome (e.g. the expanded repertoire of insulator proteins in Drosophila) and in the function of 3D structures themselves (e.g. the KNOT, which safeguards plant genomes against invasive DNA elements) [11, 12].

Moving on to a more structural focus, Canat, Veillet and colleagues discuss how genomicsbased assays have revealed how the eukaryotic genome is positioned within the cell nucleus. Particularly, they discuss how the interactions of genomic regions with nuclear landmarks like the nucleolus, nuclear lamina, nuclear pores and pericentromeric heterochromatin act as major drivers for the separation of active and inactive regions in the genome. Moreover, they discuss the dynamic interplay between these interactions with nuclear landmark, the changes in transcriptional regulation and the self-organizing properties of the genome within the nuclear space [13]. This latter aspect of self-organization is further discussed in following reviews about polymer-based modeling $[14,15]$. First, Brackley and Marenduzzo introduce how polymer physics-inspired computer simulations have revealed how bridging-induced microphase separation can explain the self-self aggregation that is commonly observed in 3D genome organization. Moreover, they discuss how such simulations can be used to make predictions about the active nature of biological processes, based on the dynamics observed in imaging experiments [14]. Next, Ghosh and Jost discuss how biophysical modeling has revealed "loop extrusion" as a second mechanism that has a major effect on 3D genome organization. Simulations of dynamic loop extrusion, incorporating proteins from the Structural Maintenance of Chromosome family (SMC; e.g. the Cohesin complex) and stabilization by insulator proteins (e.g. CTCF), were able to explain the emergence of TAD structure within Hi-C maps, thus providing important guidance for experimental investigations [15]. 
The last two contributions in this special issue focus on practical consequences of 3D genome organization, although from a very different angle. Anania and Lupiáñez summarize current insights into how 3D genome organization is implicated in human disease and developmental defects. Whereas nearly all currently known examples are ultimate caused by rewiring of chromatin loops, in many cases the causative event can be traced back to either a disruption of structuring factors, usually resulting in a more global reorganization of genome architecture, or mutations in the DNA sequence, with usually more local effects [16]. Finally, Xu and Dixon discuss how the unique nature of Hi-C data can be exploited to extract information about genomes that is difficult to assess by conventional sequencing approaches. In 3C-based assays, including $\mathrm{Hi}-\mathrm{C}$, distal genomic fragments are linked based on close spatial proximity within the same cell and, particularly in mammals, on the same copy of a chromosome. This review therefore details how the use of Hi-C can be extended to facilitate genome-assembly, the identification of structural variants, the phasing of haplotypes in di- or polyploid organisms and isolation of individual genome sequences from complex populations of cells [17].

In conclusion, this special issue provides a comprehensive overview of the field of 3D genome organization, as provided by a new generation of scientists. The reviews touch on a wide range of topics, covering technology, computational approaches, structural aspects, biological systems and human disease. This collection can thus serve as an excellent introduction to this young, dynamic and exciting field, both by providing an overview of the current state of affairs and by providing hints of future directions.

\section{Acknowledgment}

I would like to thank all the authors and anonymous reviewers whose contributions were essential for putting this special issue together. I also would like to thank Dr. Alison Bentley from the Briefings Editorial Office for her support in the process.

Daan Noordermeer

Chromatin Dynamics group 
102 1. Dekker J., Rippe K., Dekker M., Kleckner N. Capturing chromosome conformation. Science. 2002;295(5558):1306-11. Epub 2002/02/16. doi: 10.1126/science.1067799. PubMed PMID: 11847345. 2. Lieberman-Aiden E., van Berkum N.L., Williams L., Imakaev M., Ragoczy T., Telling A., et al. Comprehensive mapping of long-range interactions reveals folding principles of the human genome. Science. 2009;326(5950):289-93. Epub 2009/10/10. doi: 10.1126/science.1181369. PubMed PMID: 19815776; PubMed Central PMCID: PMCPMC2858594.

109 3. Tolhuis B., Palstra R.J., Splinter E., Grosveld F., de Laat W. Looping and interaction between 110 hypersensitive sites in the active beta-globin locus. Mol Cell. 2002;10(6):1453-65. Epub 2002/12/31. 111 doi: 10.1016/s1097-2765(02)00781-5. PubMed PMID: 12504019.

112 4. Dixon J.R., Selvaraj S., Yue F., Kim A., Li Y., Shen Y., et al. Topological domains in 113 mammalian genomes identified by analysis of chromatin interactions. Nature. 2012;485(7398):376-80.

114 Epub 2012/04/13. doi: 10.1038/nature11082. PubMed PMID: 22495300; PubMed Central PMCID: 115 PMC3356448.

116 5. Nora E.P., Lajoie B.R., Schulz E.G., Giorgetti L., Okamoto I., Servant N., et al. Spatial 117 partitioning of the regulatory landscape of the X-inactivation centre. Nature. 2012;485(7398):381-5. 118 Epub 2012/04/13. doi: 10.1038/nature11049. PubMed PMID: 22495304.

119 6. Phillips-Cremins J.E., Sauria M.E., Sanyal A., Gerasimova T.I., Lajoie B.R., Bell J.S., et al. 120 Architectural protein subclasses shape 3D organization of genomes during lineage commitment. Cell. 2013;153(6):1281-95. Epub 2013/05/28. doi: 10.1016/j.cell.2013.04.053. PubMed PMID: 23706625; PubMed Central PMCID: PMC3712340. 7. Rao S.S., Huntley M.H., Durand N.C., Stamenova E.K., Bochkov I.D., Robinson J.T., et al. A 3D map of the human genome at kilobase resolution reveals principles of chromatin looping. Cell. 2014;159(7):1665-80. Epub 2014/12/17. doi: 10.1016/j.cell.2014.11.021. PubMed PMID: 25497547; PubMed Central PMCID: PMCPMC5635824.

1278 U Übelmesser N., Papantonis A. Technologies to study spatial genome organization: beyond 3C. 128 Brief Funct Genom. 2019;18(6):395-401. doi: 10.1093/bfgp/elz019.

129 9. Pachano T., Crispatzu G., Rada-Iglesias A. Polycomb proteins as organizers of 3D genome 130 architecture in embryonic stem cells. Brief Funct Genom. 2019;18(6):358-66. doi: $131 \quad 10.1093 / \mathrm{bfgp} / \mathrm{elz022}$.

132 10. van Schoonhoven A., Huylebroeck D., Hendriks R.W., Stadhouders R. 3D genome 133 organization during lymphocyte development and activation. Brief Funct Genom. 2019. doi: 134 10.1093/bfgp/elz030.

135 11. Grob S. Three-dimensional chromosome organization in flowering plants. Brief Funct Genom. 136 2019. doi: 10.1093/bfgp/elz024. 
137 12. Moretti C., Stévant I., Ghavi-Helm Y. 3D genome organisation in Drosophila. Brief Funct 138 Genom. 2019. doi: 10.1093/bfgp/elz029.

139 13. Canat A., Veillet A., Bonnet A., Therizols P. Genome Anchoring To Nuclear landmarks 140 Drives Functional Compartmentalization of the Nuclear Space. Brief Funct Genom. 2020.

141 14. Brackley C.A., Marenduzzo D. Bridging-induced microphase separation: photobleaching 142 experiments, chromatin domains and the need for active reactions. Brief Funct Genom. 2020. doi: 143 10.1093/bfgp/elz032.

144 15. Ghosh S.K., Jost D. Genome organization via loop extrusion, insights from polymer physics 145 models. Brief Funct Genom. 2019. doi: 10.1093/bfgp/elz023.

146 16. Anania C., Lupiáñez D.G. Order and Disorder: Abnormal 3D Chromatin Organization in 147 Human Disease. Brief Funct Genom. 2020.

148 17. Xu Z., Dixon J.R. Genome reconstruction and haplotype phasing using chromosome 149 conformation capture methodologies. Brief Funct Genom. 2019. doi: 10.1093/bfgp/elz026. 